\title{
Sheet Resistance Measurement of Thin Metal Films Using Reflection-Mode THz-TDS
}

\author{
Kelner, Roy; Buron, Jonas Due; Uhd Jepsen, Peter
}

Link to article, DOI:

10.1109/IRMMW-THz50926.2021.9567339

Publication date:

2021

Document Version

Peer reviewed version

Link back to DTU Orbit

Citation (APA):

Kelner, R., Buron, J. D., \& Uhd Jepsen, P. (2021). Sheet Resistance Measurement of Thin Metal Films Using Reflection-Mode THz-TDS. Abstract from $46^{~}{ }^{2}$ International Conference on Infrared, Millimeter and Terahertz Waves, Chengdu, China. https://doi.org/10.1109//RMMW-THz50926.2021.9567339

\section{General rights}

Copyright and moral rights for the publications made accessible in the public portal are retained by the authors and/or other copyright owners and it is a condition of accessing publications that users recognise and abide by the legal requirements associated with these rights.

- Users may download and print one copy of any publication from the public portal for the purpose of private study or research.

- You may not further distribute the material or use it for any profit-making activity or commercial gain

- You may freely distribute the URL identifying the publication in the public portal

If you believe that this document breaches copyright please contact us providing details, and we will remove access to the work immediately and investigate your claim 


\title{
Sheet Resistance Measurement of Thin Metal Films Using Reflection-Mode THz-TDS
}

\author{
Roy Kelner ${ }^{1}$, Jonas Due Buron ${ }^{2}$, and Peter Uhd Jepsen ${ }^{1}$ \\ ${ }^{1}$ DTU Fotonik, Department of Photonics Engineering, Technical University of Denmark, Ørsteds Plads, \\ DK-2800 Kongens Lyngby, Denmark \\ ${ }^{2}$ CAPRES - a KLA Company, Scion-DTU, Diplomvej 373B, DK-2800 Kongens Lyngby, Denmark
}

\begin{abstract}
Micro four-point probe technology can reliably be used to measure the sheet resistance of thin metal films, with great accuracy and repeatability. In this work, we investigate the suitability of using reflection-mode teraherz time-domain spectroscopy for the same task. The agreement between the two methods places reflection-mode terahertz time-domain spectroscopy as a viable tool for thin metal film analysis.
\end{abstract}

\section{INTRODUCTION}

$\mathrm{T}_{\mathrm{a}}$ ERAHERTZ time-domain spectroscopy (THz-TDS) [1] is a proven method for the characterization of thin metal films in a non-destructive, contactless fashion [2,3]. Commonly, THz-TDS measurements are done in transmission (e.g., [2,3]). Reflection-mode THz-TDS has its merits, but is challenging, as demonstrated in [4] for graphene measurements. Here, we demonstrate accurate measurement of the dc sheet resistance, $R_{s, d c}$, of titanium (Ti) thin metal films on a silicon ( $\mathrm{Si}$ ) substrate, using reflection-mode THz-TDS. The results are benchmarked against values obtained using Capres A/S stateof-the-art micro four-point probe (M4PP) technology.

\section{RESULTS}

A THz-TDS system (Toptica TeraFlash Pro) was used to acquire time traces reflected from Ti thin metal films (5 to 15 $\mathrm{nm}$ in thickness) on an Si substrate, as schematically shown in Fig. 1(a) and (b). Time traces, for various Ti film thicknesses and Si substrate only, are shown in Fig. 1(c).

The complex, frequency dependent sheet conductance, $\sigma_{s}(\omega)$, can be calculated using the formula

$$
\text { (1) } \sigma_{s}(\omega)=\frac{\left(1+n_{s u b}\right)[1-\tilde{R}(\omega)]}{Z_{0}\left[\tilde{R}(\omega)+\left(1+n_{s u b}\right) /\left(1-n_{s u b}\right)\right]}
$$

where $\tilde{R}(\omega)$ is the ratio of the Fourier transforms of the thin film trace and the substrate reference trace, $n_{s u b}$ is the refractive index of the substrate and $Z_{0}$ is the free space impedance. To reliably extract the dc sheet resistance value, $R_{s, d c}=1 / \sigma_{s, d c}$, from the THz-TDS data, our algorithm relies on Eq. (1) and additional concepts that result from a Drude model-based reasoning (note that $\sigma_{s}(\omega) \approx \sigma_{s, d c} /(1-i \omega \tau)$, according to the Drude model). These concepts help mitigate the possibly strong influence of minute misalignments between the thin film and substrate-only reference measurements. Each thin metal film was measured at up to 25 different points using both M4PP and THz-TDS. Results are summarized in Table 1, showing mean values obtained by M4PP and THz-TDS in good agreement and with comparable standard deviations (SDs). We believe that these results demonstrate that reflection-mode THz-TDS can serve as a viable tool for thin metal film analysis.

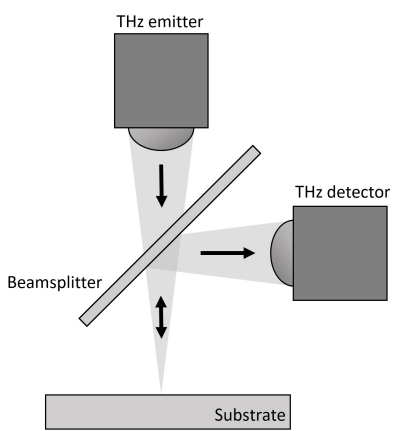

(a)



(b)

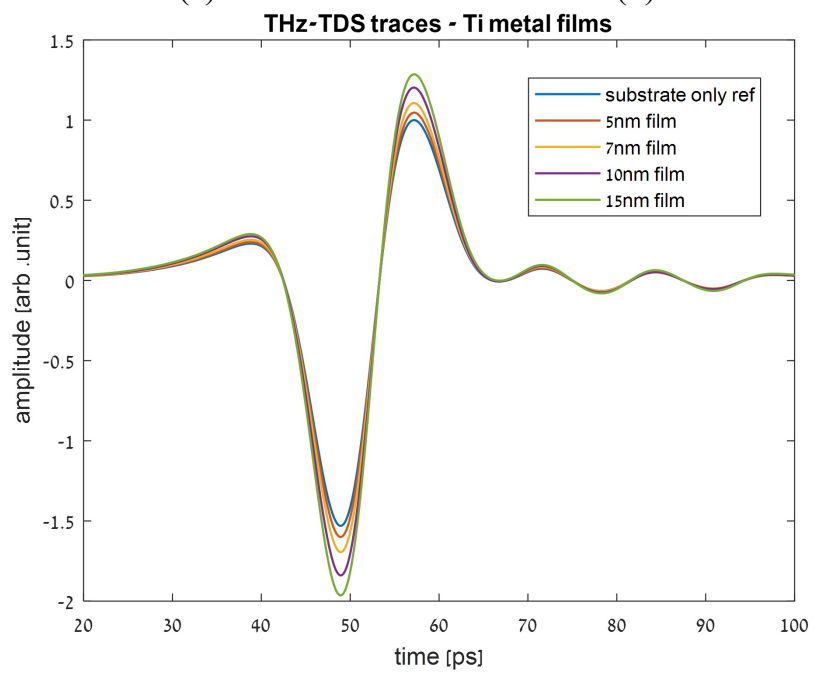

(c)

Fig. 1. (a), (b) Simplified schematic of the THz-TDS experimental setup and (c) thin film THz-TDS traces.

\begin{tabular}{|c|c|c|c|c|c|c|c|c|}
\hline Thickness & \multicolumn{2}{|c|}{$5 \mathrm{~nm}$} & \multicolumn{2}{c|}{$7 \mathrm{~nm}$} & \multicolumn{2}{c|}{$10 \mathrm{~nm}$} & \multicolumn{2}{c|}{$15 \mathrm{~nm}$} \\
\hline & mean & SD & mean & SD & mean & SD & mean & SD \\
\hline M4PP & 1522.4 & 50.62 & 516.45 & 6.26 & 272.64 & 2.51 & 166.24 & 1.91 \\
\hline THz-TDS & 1481.5 & 69.59 & 513.02 & 11.17 & 268.42 & 3.41 & 164.13 & 2.69 \\
\hline
\end{tabular}

Table 1. Sheet resistance mean and standard deviation (SD) values $[\Omega]$ measured using M4PP and THz-TDS.

\section{REFERENCES}

[1] P. U. Jepsen, D. G. Cooke, and M. Koch, "Terahertz spectroscopy and imaging - Modern techniques and application," Laser Photonics Rev. 5(1), 124-166, 2011.

[2] N. Laman and D. Grischkowsky, "Terahertz conductivity of thin metal films," Appl. Phys. Lett. 93, 051105, 2008.

[3] Z. Wang, Y. Han, N. Xu, L. Chen , C. Li, L. Wu, and W. Zhang, "Characterization of thin metal films using Terahertz spectroscopy," IEEE Trans. Terahertz Sci. and Tech. 8(2), 161-164, 2018.

[4] H. Lin, P. Braeuninger-Weimer, V. S. Kamboj, D. S. Jessop, R. Degl'Innocenti, H. E. Beere, D. A. Ritchie, J. A. Zeitler, and S. Hofmann, "Contactless graphene conductivity mapping on a wide range of substrates with terahertz time-domain reflection spectroscopy," Sci. Rep. 7, 10625, 2017. 